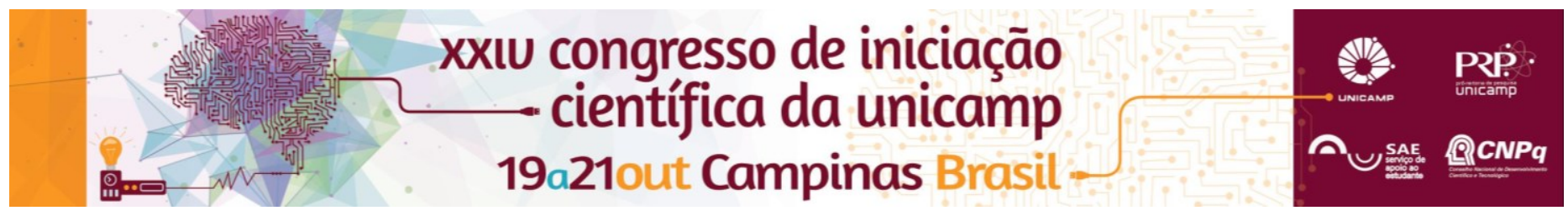

\title{
Estudos Geométricos e desenvolvimento criativo de Elementos Arquitetônicos Modulares
}

\author{
Beatriz Marques Bigotto*, Robert Willian Polli*, Rogério Fachinetti Júnior*, Samuel H S Azevedo*, Vinícius \\ Augusto N. Gianezi*, Ana Lúcia N.C. Harris, Nicolas Doi, Leandro H. S. Domingos, Suellen Ribeiro.
}

\begin{abstract}
Resumo
Este projeto faz parte de um conjunto de pesquisas, voltadas ao estudo da forma, tendo como o objetivo principal a difusão de conceitos teóricos e interdisciplinaridade no desenvolvimento e produção de elementos arquitetônicos. Isto se dá, com um fio condutor da geometria modular, adequada ao uso de materiais alternativos, visando, tanto a difusão das técnicas de produção, quanto à conscientização sobre a criação de objetos com incorporação de criatividade, personalidade e qualidade de design.
\end{abstract}

\section{Palavras-chave}

modelagem, design, interdisciplinar.

\section{Introdução}

O desenvolvimento do processo de projeto até a produção de elementos arquitetônicos percorre um caminho caracteristicamente interdisciplinar. A familiarização deste processo influencia diretamente na qualidade final do produto. Esta pesquisa, vinculada ao programa com bolsistas PIBIC-EM, foi estruturada em atividades sequenciais com o intuito de se percorrer por este caminho. Cada uma das atividades teve como componentes básicos fundamentações teóricas, pesquisa e desenvolvimento prático de atividades.

Foram aplicadas ao todo 12 atividades, que permearam, entre outros, nos seguintes assuntos: geometria; modularidade; origami; modelagem física; modelagem digital; prototipagem rápida e automação.

As atividades foram realizadas em laboratórios de informática e no Laboratório de Modelos e Maquetes da FEC.

\section{Resultados e Discussão}

Em cada uma das atividades, os bolsistas tiveram acesso a diferentes temas e assimilaram-nos a partir de atividades práticas. Os resultados alcançados foram além das expectativas iniciais, o que demonstrou a potencialidade destes bolsistas quando estimulados pela aplicação de atividades práticas e interdisciplinares.

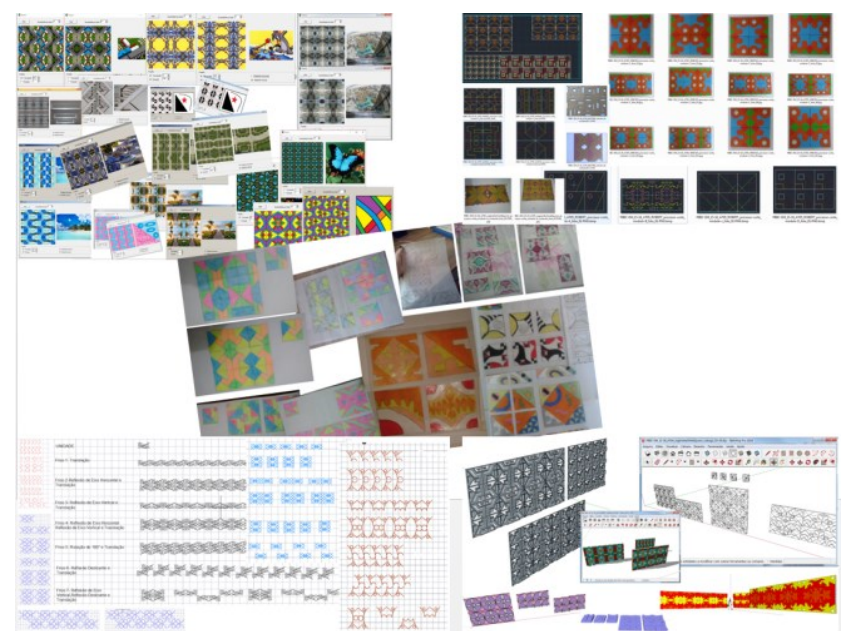

Figura 1. Atividades dos bolsistas AT01-AT05

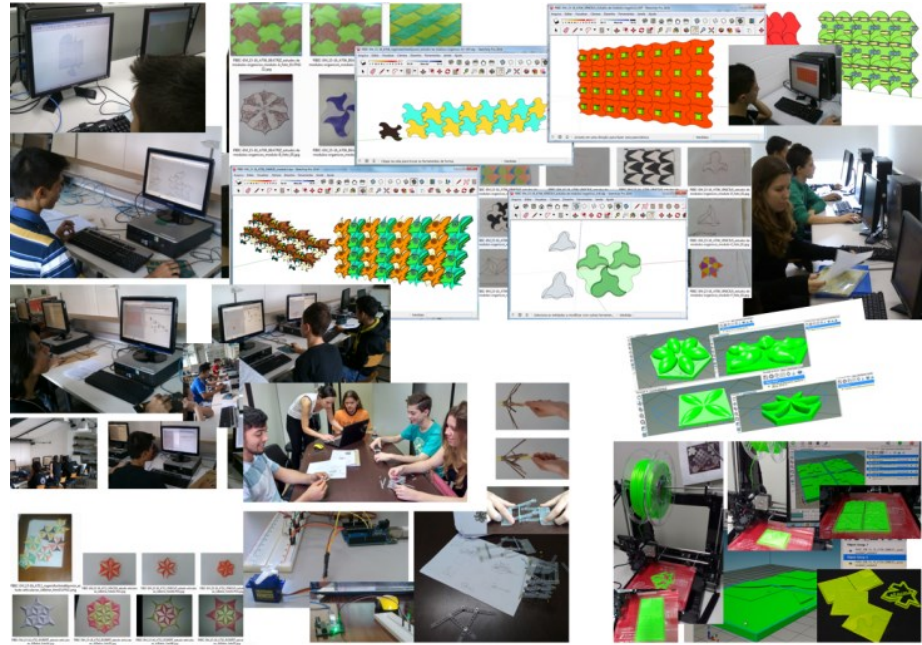

Figura 2. Atividades dos bolsistas AT06-AT12

As Figuras 1 e 2 ilustram as atividades desenvolvidas pelos bolsistas no período do projeto.

\section{Conclusões}

A pluralidade dos assuntos abordados, girando em torno de atividades, cuja linha base foi o desenvolvimento de elementos com foco na abstração formal, resultou em uma sequência de aprendizagens que, acredita-se ter contribuído positivamente para a formação dos bolsistas, cujo interesse e participação foram crescentes ao longo do período.

\section{Agradecimentos}

O apoio do programa PIBIC-EM foi fundamental para a realização desta pesquisa. Aos bolsistas BAS/UNICAMP Suellen e Leandro por sua colaboração.

HARRIS, Ana Lúcia N.C.; ANAF, Márcia. A interdisciplinaridade no desenvolvimento de elementos arquitetônicos: um experimento com bolsistas do ensino médio. In: GRAPHICA 2013- CONGRESSO INTERNACIONAL DE ENGENHARIA GRÁFICA NAS ARTES E NO DESENHO, 10; SIMPÓSIO NACIONAL DE GEOMETRIA DESCRITIVA E DESENHO TÉCNICO, 21. Anais, 2013, Florianópolis. <último acesso 2016> http://www.fec.unicamp.br/ laforma/pages/laforma-pb.html 